\title{
Efficacy of 5-Fluorouracil in the Treatment of Pterygium
}

\author{
Sobia U. Shah ${ }^{1}$, Tanveer Ahmed ${ }^{1,2}$, Anum Badar ${ }^{3}$, Maeirah Shafique ${ }^{4}$, Sidra Malik ${ }^{5}$, Bushra Aaqil ${ }^{6}$ \\ 1. Ophthalmology, Combined Military Hospital (CMH) Lahore Medical College, National University of Medical Sciences \\ (NUMS), Lahore, PAK 2. Ophthalmology, Combined Military Hospital (CMH) Lahore, Lahore, PAK 3. Ophthalmology, \\ Combined Military Hospital (CMH) Rawalakot, Rawalakot, PAK 4. Ophthalmology, Combined Military Hospital (CMH) \\ Abbottabad, Abbottabad, PAK 5. Ophthalmology, Pakistan Air Force (PAF) Faisal Base Karachi, Karachi, PAK 6. \\ Ophthalmology, Ayub Medical College, Abbottabad, PAK
}

Corresponding author: Sobia U. Shah, sobiz_88@yahoo.com

\section{Abstract}

\section{Objective}

To determine the efficacy of 5-Fluorouracil (FU) in the treatment of pterygium.

\section{Methodology}

After meeting the inclusion criteria 101 patients were enrolled in this study. Informed consent and demographic information was taken from all the patients. Patients underwent ophthalmic clinical examination that included slit lamp examination to grade pterygium. Before starting 5-FU injections, all topical medication was stopped. After four weeks the effects of 5-FU and its efficacy was noted. The patients were reviewed again after six months to note any recurrence. All the collected data was entered and analyzed on Statistical Package for Social Sciences (SPSS) version 20 (IBM Corp., Armonk, NY).

\section{Results}

In our study the mean age of the patients was $37.74 \pm 10.15$ years, male to female ratio of the patients was 1.06:1. The primary type of pterygium was noted in 54 (53.5\%) and recurrent was noted in 47 (46.5\%) patients. The efficacy achieved in 88 (87.13\%) patients, four had recurrence of pterygium and of 101 patients 26 underwent surgical excision.

\section{Conclusion}

The use of 5-FU is safe and effective for the treatment of pterygium and it can be implemented as a primary treatment especially in the hot temperate zone where it is very common and aggressive with high recurrence rate. 5-FU not only halts its progression but also reduces the size and vascularity thus decreasing the need for surgery and steroid use and preventing recurrence.

Review began 01/06/2021 Review ended 01/11/2021 Published 01/12/2021

\section{() Copyright 2021}

Shah et al. This is an open access article distributed under the terms of the Creative Commons Attribution License CC-BY 4.0., which permits unrestricted use, distribution, and reproduction in any medium, provided the original author and source are credited.
Categories: Ophthalmology

Keywords: pterygium, 5 fluorouracil, efficacy, primary pterygium, recurrent pterygium, $5 \mathrm{fu}$

\section{Introduction}

Pterygium is a triangular growth of fibrovascular conjunctival tissue that typically starts medially on the nasal conjunctiva and extends laterally on to the cornea. It refers to shape of the tissue which looks like an insect wing [1]. Pterygium is unlikely to threaten visual acuity unless it approaches cornea nevertheless it can be a cause of concern to the patients because of abnormal appearance it confers upon the eye and the irritation that is often associated with it [2]. Prevalence of pterygium varies from $0.7 \%$ to $33 \%$, being more common in males. It is associated with chronic sun exposure and specifically to ultraviolet light, thus it is more commonly seen in outdoor workers and in tropic and equatorial zone [3]. The standard treatment is excision with autologus conjunctival graft to cover the defect [4]. Recurrence is the most common complication after pterygium surgery which rates from 10 to $80 \%$ depending on excision procedure [3-5]. 5Fluorouracil (5-FU), an anti-metabolite, is a pyrimidine analogue that causes apoptosis of fibroblasts by interfering with DNA and RNA synthesis of fibroblasts in the tenons capsule. In ophthalmology it is being used widely due to its anti-scarring properties in glaucoma filtering surgery and also in cases of recurrent pterygium [6,7]. Studies show that $93.3 \%$ patients had regression of fibrovascular tissue (thickness and vascularity) and arrest of progression following a dose of $0.1-0.2 \mathrm{ml}$ of 5-FU in recurrent pterygium $[1,8]$.

The rationale of this study is to see the efficacy of 5-FU on pterygium in our population and to determine whether or not 5-FU should be made a part of primary treatment of pterygium. Work has been done to see the effect of 5-FU in halting pterygium recurrence but very little work has been done where it is being assessed as a primary treatment modality thus decreasing the excessive use of steroids before and after 


\section{Cureus}

surgery, preventing recurrence and need of surgical excision.

\section{Materials And Methods}

Patients reporting to outpatient department with pterygium of 2 or more millimeter over cornea with a grade of 2 or 3 were included in the study. Grade was assigned according to the following criteria: GRADE 1 (Atrophic pterygium) (Episcleral vessels clearly seen), GRADE 2 (Intermediate pterygium) (Episcleral vessels not clearly seen), GRADE 3 (Fleshy pterygium) (Episcleral vessels obscured). Patients with recent history of ocular trauma, corneal degeneration, scarring or ectasia were excluded. History was taken and age, gender, occupation, recurrence or any previous treatment modalities were documented. Patients underwent ophthalmic clinical examination that included slit lamp examination to grade pterygium. Case note entries were used to assess improvement after injection in both primary and recurrent pterygium. Approval was taken from ethical committee and informed written consent was taken from all individuals. Before starting 5-FU injections, all topical medications were stopped. $0.1 \mathrm{ml}$ of 5-FU (5 mg) in $1 \mathrm{ml}$ syringe was given intralesional under topical anesthesia. One to two drops of $5 \%$ povidone iodine was instilled in conjunctival sac 5 min before injection that was given in outpatient clinic using slit lamp. After injection Moxifloxacin was instilled and given Q.I.D for three days. Total of three injections were given at weekly intervals with follow-up after four weeks and effects of 5-FU noted and efficacy was determined in terms of improvement in the grade of pterygium $\geqslant 1$ grade on slit lamp examination on follow-up visits after four weeks of last injection. The patients were seen after six months to record any recurrence in terms of a grade increase of $>1$. All the data was recorded on a specially designed proforma. Data was entered and analyzed by using Statistical Package for Social Sciences (SPSS) version 20 (IBM Corp., Armonk, NY). Pre- and postinjection clinical appearance and grading of pterygium was compared by chi-square test and frequency distribution was used to determine efficacy. Effect modifiers like age, steroid use and other ocular pathology were controlled through stratification.

\section{Results}

The mean age of the patients was $37.74 \pm 10.15$ years with minimum and maximum ages of 21 and 55 years, respectively. There were $52(51.49 \%)$ males and 49 (48.51\%) females. The male to female ratio of the patients was $1.06: 1$. The study results showed that the primary type of pterygium was noted in $54(53.5 \%)$ and recurrent was noted in 47 (46.5\%) patients (Table 1$)$.

\begin{tabular}{|ll|l|l|}
\hline & & Frequency & Percent \\
\hline & Primary & 54 & 53.5 \\
Type & Recurrent & 47 & 46.5 \\
& Total & 101 & 100.0 \\
\hline
\end{tabular}

TABLE 1: Frequency distribution of type of pterygium

The intermediate grade at baseline was noted in 46 (45.5\%) patients and fleshy grade at baseline was noted in $55(54.5 \%)$ patients. After 4 th weeks it was found that 88 (87.1\%) patients had improvement in their grade at baseline by $\geqslant 1$ and 13 (12.9\%) patients did not have any improvement in the grade at baseline a month after three injections of 5-FU. Post treatment cases showing higher number in grade 2 as out of 101 patients in the study 55 had a grade 3 pterygium which improved to grade 2 or 1 (Table 2). 


\section{Cureus}

\begin{tabular}{|c|c|c|c|c|c|}
\hline \multirow{2}{*}{ Clinical Appearance } & \multicolumn{2}{|c|}{ Primary Pterygium } & \multicolumn{2}{|c|}{ Recurrent Pterygium } & \multirow{2}{*}{$P<0.001$ significant } \\
\hline & Pre-Treatment & Post-Treatment & Pre-Treatment & Post-Treatment & \\
\hline Grade 1 & 0 & 27 & 0 & 15 & $P<0.001$ \\
\hline Grade 2 & 29 & 23 & 17 & 27 & $P<0.001$ \\
\hline Grade 3 & 25 & 4 & 30 & 5 & $P<0.001$ \\
\hline Total & 54 & & 47 & & 101 \\
\hline
\end{tabular}

TABLE 2: Frequency distribution of various grades of pterygium before and after treatment.

Hence efficacy was achieved in 88 (87.13\%) patients but not achieved in 13 (12.87\%) patients (Figure 1).

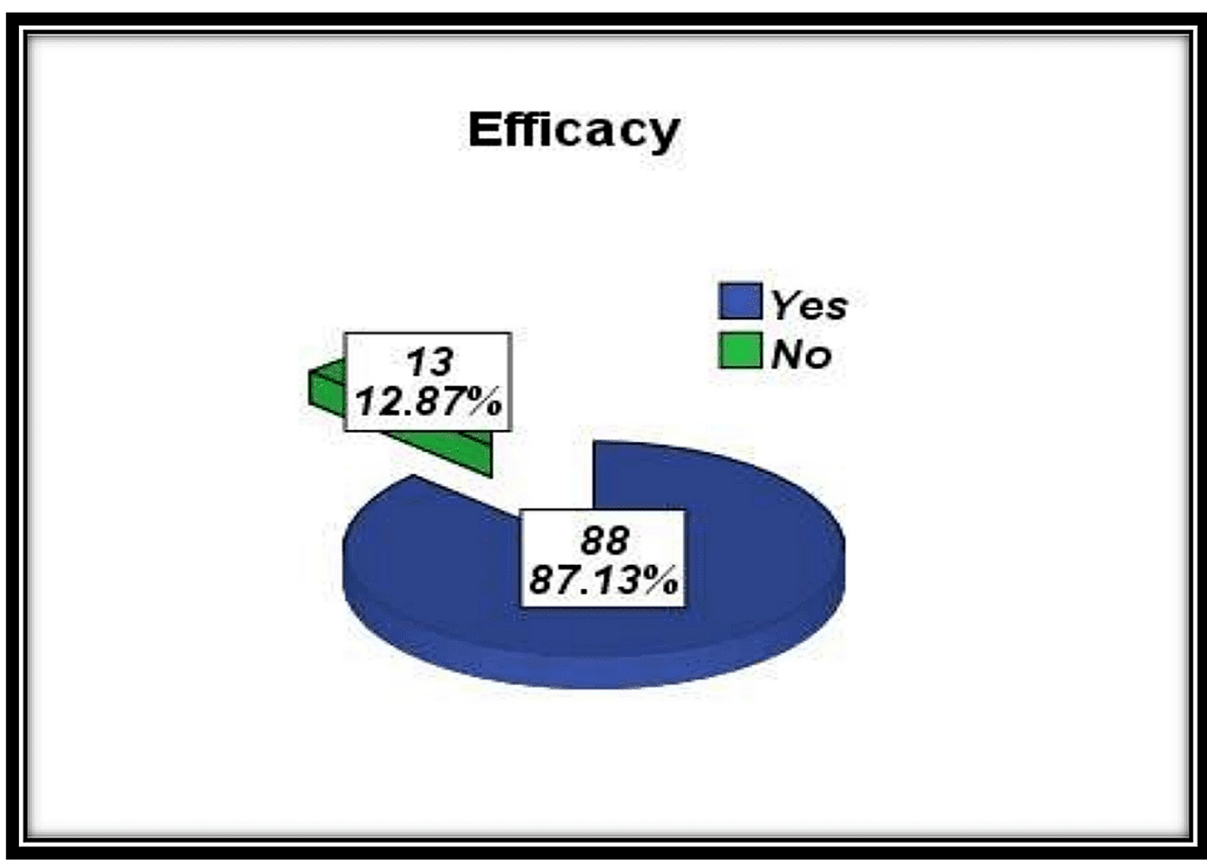

FIGURE 1: Efficacy of 5-FU used as a primary treatment of pterygium.

The study results showed $\leqslant 30$ years patients were 28 in which efficacy achieved in 23 cases and it was not achieved in five cases. Similarly $>30$ years patients were 73 in which efficacy achieved in 65 cases and it was not achieved in eight cases. Statistically insignificant difference found between the efficacy was age, i.e., pvalue $=0.354$ (Table 3).

\begin{tabular}{|c|c|c|c|c|}
\hline & & \multicolumn{2}{|c|}{ Efficacy } & \multirow{2}{*}{ Total } \\
\hline & & Yes & No & \\
\hline \multirow{2}{*}{ Age (years) } & $\leq 30$ & 23 & 5 & 28 \\
\hline & $>30$ & 65 & 8 & 73 \\
\hline Total & & 88 & 13 & 101 \\
\hline
\end{tabular}

TABLE 3: Comparison of efficacy with age. 
The study results showed the male patients were 52 in which efficacy achieved in 43 cases and it was not achieved in nine cases. Similarly the female patients were 49 in which efficacy achieved in 45 cases and it was not achieved in four cases. Statistically insignificant difference found between the efficacy was gender, i.e., p-value $=0.170$ (Table 4$)$.

\begin{tabular}{|c|c|c|c|c|}
\hline & & \multicolumn{2}{|c|}{ Efficacy } & \multirow{2}{*}{ Total } \\
\hline & & Yes & No & \\
\hline \multirow{2}{*}{ Gender } & Male & 43 & 9 & 52 \\
\hline & Female & 45 & 4 & 49 \\
\hline Total & & 88 & 13 & 101 \\
\hline
\end{tabular}

TABLE 4: Comparison of efficacy with gender.

The study results showed the patients with primary pterygium were 54 in which efficacy achieved in 48 cases and it was not achieved in six cases. Similarly the patients with recurrent pterygium were 47 in which efficacy achieved in 40 cases and it was not achieved in seven cases. Statistically insignificant difference found between the efficacy was type of pterygium, i.e., p-value $=0.571$ (Table 5).

\begin{tabular}{|c|c|c|c|c|}
\hline & & \multicolumn{2}{|c|}{ Efficacy } & \multirow{2}{*}{ Total } \\
\hline & & Yes & No & \\
\hline \multirow{2}{*}{ Type } & Primary & 48 & 6 & 54 \\
\hline & Recurrent & 40 & 7 & 47 \\
\hline Total & & 88 & 13 & 101 \\
\hline
\end{tabular}

TABLE 5: Comparison of efficacy with type of pterygium.

On six-month post injection review only four patients in intermediate Grade 2 developed a fleshy grade 3 pterygium and total 26 patients underwent surgical excision of which 13 were those who showed no improvement after the injections.

\section{Discussion}

The standard treatment of pterygium in the literature is surgical excision with a conjunctival graft to cover the defect but recurrence remains as the most common complication after excision [8]. Several adjunctive treatments have been employed to reduce recurrences [9-15]. In our study, we used 5-Fluorouracil, a pyrimidine analogue that causes apoptosis of fibroblasts and has anti-scarring properties. Studies are available that prove its efficacy to treat recurrence or as an adjunct but no study is present where it is used as a primary treatment modality. A study by Said et al. presented that the use of weekly intra-lesional 5-FU injections for the treatment of recurrent pterygium is safe and effective in limiting the progression and inducing the regression of recurrent pterygium [1]. The number of injections can be tailored according to clinical need. Another study showed that $93.3 \%$ patients showed regression of fibrovascular tissue (thickness and vascularity) and arrest of progression following a dose of 0.1-0.2 $\mathrm{ml}$ of 5-FU in recurrent pterygium [8]. A single intra-operative application of mitomycin C (MMC) has been shown to be effective in reducing the recurrence of pterygium [16]. A study by Prabhasawat et al. resulted that the 5-FU was significantly $(\mathrm{P}=$ 0.001) more effective in inhibiting the recurrence of pterygium injected weekly for two weeks compared with the control group at follow-up [17]. Kaplan-Meier survival analysis showed that the recurrence-free period of pterygium in the 5 -FU group was significantly $(\mathrm{P}=0.005)$ longer than that of the control group. One study by Valezi et al. suggests that intraoperative infiltration of 5-FU is safe for treatment of pterygium and there is no statistically significant difference between the intraoperative and topical of application of 5-FU, however, the high recurrence rate indicated that other studies would be necessary to show the concentration/dose to better prevent it [18]. Ibrahim and Nada demonstrated that the infiltration of 5-FU rather than topical application as an adjuvant to pterygium surgery is easy, time saving, and does not necessitate copious irrigation with saline as with topical application with comparable results and postoperative complications [19]. Maldonado et al. studied the efficacy of a low dose of intra-operative 5-FU [20]. They concluded that this was ineffective in preventing recurrence. This is probably because of 
inadequate treatment both in terms of dose and duration, suggesting that a single injection is not sufficient. Adverse effects seen with 5-FU are epithelial keratopathy due to inhibition of mitosis of corneal epithelium but is mostly seen after its use in glaucoma filtering surgery [21]. In our study no epithelial toxicity, sclera thinning or conjunctivitis was seen. Injection-related rather than drug-induced events were noted like stinging sensation and subconjunctival hemorrhage at the site that resolved in around two weeks. Limitation of the study was a longer follow-up that is required to see any recurrence. Grade 1 pterygium and those not yet approaching the cornea were excluded, can be taken into consideration and number of injections can be tailored according to the clinical appearance.

\section{Conclusions}

The use of 5-FU is safe and effective for the treatment of pterygium and it can be used as a primary treatment as the results are promising especially in regards to its improvement in the clinical appearance, prevention of recurrence and decreasing the need of surgical excision and excessive use of steroids which are being used both to treat pterygium and after surgical excision. Studies need to be done to see the response in different geographical regions as sun exposure, occupation and region play an important role in the progression of pterygium. Also cases of pterygium which have not yet approached the cornea can be considered in future studies to see how 5-FU halts its progression with tailored number of injections according to the clinical appearance.

\section{Additional Information \\ Disclosures}

Human subjects: Consent was obtained by all participants in this study. Research Review Board Combined Military Hospital Lahore issued approval 151/2020. The Research Review Board Combined Military Hospital Lahore has no objection on carrying out of study on research article titled "Efficacy of 5 Fluorouracil in the Treatment of Pterygium". Animal subjects: All authors have confirmed that this study did not involve animal subjects or tissue. Conflicts of interest: In compliance with the ICMJE uniform disclosure form, all authors declare the following: Payment/services info: All authors have declared that no financial support was received from any organization for the submitted work. Financial relationships: All authors have declared that they have no financial relationships at present or within the previous three years with any organizations that might have an interest in the submitted work. Other relationships: All authors have declared that there are no other relationships or activities that could appear to have influenced the submitted work.

\section{References}

1. Said D, Faraj L, Elalfy M, et al.: Intra-lesional 5 fluorouracil for the management of recurrent pterygium . Eye. 2013, 27:1123-1129. 10.1038/eye.2013.135

2. Durkin SR, Abhary S, Newland HS, Selva D, Aung T, Casson RJ: The prevalence, severity and risk factors for pterygium in central Myanmar: the Meiktila Eye study. Br J Ophthalmol. 2008, 92:25-29.

3. Jiao W, Zhou C, Wang T, et al.: Prevalence and risk factors for pterygium in rural older adults in Shandong Province of China: a cross-sectional study. Biomed Res Int. 2014, 2014:658648. 10.1155/2014/658648

4. Chui J, Coroneo MT, Tat LT, Crouch R, Wakefield D, Di Girolamo N: Ophthalmic pterygium: a stem cell disorder with premalignant features. Am J Pathol. 2011, 178:817-827. 10.1016/j.ajpath.2010.10.037

5. Hameed HT: Rotational flap versus simple conjunctival excision in pterygium treatment . Kufa Med J. 2009, 12:380-381.

6. Sutphin JE: Basic and Clinical Science Course: External Disease and Cornea. American Academy of Ophthalmology, San Francisco; 2008.

7. Brazowski E, Eytan K, Eisenthal A: In vitro modulation of interleukin-2-mediated human peripheral mononuclear cell proliferation and antitumor cytotoxicity by 5-fluorouracil. Anticancer Res. 2007, 27:41354141.

8. Malik S, Khan MS, Basit I: Comparison of primary versus recurrent pterygium after intralesional 5fluorouracil. JPMA. 2016, 66:559-562.

9. Kim JC, Tseng SC: Transplantation of preserved human amniotic membrane for surface reconstruction in severely damaged rabbit corneas. Cornea. 1995, 14:473-484.

10. Al-Saikhan FI: The gene therapy revolution in ophthalmology. Saudi J Ophthalmol. 2013, 27:107-111. 10.1016/j.sjopt.2013.02.001

11. Anguria P, Kitinya J, Ntuli S, Carmichael T: The role of heredity in pterygium development . Int J Ophthalmol. 2014, 7:563-573. 10.3980/j.issn.2222-3959.2014.03.31

12. Heidelberger C, Chaudhuri N, Danneberg P, et al.: Fluorinated pyrimidines, a new class of tumour-inhibitory compounds. Nature. 1957, 179:663-666. 10.1038/179663a0

13. Caudle KE, Thorn CF, Klein TE, Swen JJ, McLeod HL, Diasio RB, Schwab M: Clinical Pharmacogenetics Implementation Consortium guidelines for dihydropyrimidine dehydrogenase genotype and fluoropyrimidine dosing. Clin Pharmacol Therapeut. 2013, 94:640-645. 10.1038/clpt.2013.172

14. Amstutz U, Froehlich TK, Largiadèr CR: Dihydropyrimidine dehydrogenase gene as a major predictor of severe 5-fluorouracil toxicity. Pharmacogenomics. 2011, 12:1321-1336. 10.2217/pgs.11.72

15. Longley DB, Harkin DP, Johnston PG: 5-fluorouracil: mechanisms of action and clinical strategies . Nat Rev Cancer. 2003, 3:330-338. 10.1038/nrc1074

16. Lam DS, Wong AK, Fan DS, Chew S, Kwok PSK, Tso MOM: Intraoperative mitomycin C to prevent recurrence of pterygium after excision: a 30-month follow-up study. Ophthalmology. 1998, 105:901-905. 


\section{Cureus}

10.1016/S0161-6420(98)95034-5

17. Prabhasawat P, Tesavibul N, Leelapatranura K, Phonjan T: Efficacy of subconjunctival 5-fluorouracil and triamcinolone injection in impending recurrent pterygium. Ophthalmology. 2006, 113:1102-1109.

10.1016/j.ophtha.2006.02.026

18. Valezi VG, Schellini SA, Viveiros MMH, Padovani CR: Safety and efficacy of intraoperative 5-fluorouracil infiltration in pterygium treatment. Arq Bras Oftalmol. 2009, 72:169-173. 10.1590/S000427492009000200007

19. Ibrahim BM, Nada WM: Intraoperative infiltration against topical application of 5-fluorouracil in pterygium treatment. Delta J Ophthalmol. 2017, 18:7. 10.4103/1110-9173.201625

20. Maldonado MJ, Cano-Parra J, Navea-Tejerina A, Cisneros AL, Vila E, Menezo JL: Inefficacy of low-dose intraoperative fluorouracil in the treatment of primary pterygium. Arch Ophthalmol. 1995, 113:1356-1357. 10.1001/archopht.1995.01100110016008

21. Wong TT, Khaw PT, Aung T, et al.: The Singapore 5-Fluorouracil Trabeculectomy Study: effects on intraocular pressure control and disease progression at 3 years. Ophthalmology. 2009, 116:175-184. 10.1016/j.ophtha.2008.09.049 